\title{
Isolation and Characterization of Photodegradation Impurity in Budesonide Drug Product Using LC-MS and NMR Spectroscopy
}

\author{
Arun Bhutnar*, Sachin Khapare, Anita Desai, Smitha Dsouza \\ Formulation Analytical Development Laboratory (FD ADL), Integrated Project Development (IPD), Cipla Ltd., \\ Mumbai, India \\ Email: *arun.bhutnar@cipla.com
}

How to cite this paper: Bhutnar, A., Khapare, S., Desai, A. and Dsouza, S. (2017) Isolation and Characterization of Photodegradation Impurity in Budesonide Drug Product Using LC-MS and NMR Spectroscopy. American Journal of Analytical Chemistry, 8, 449-461.

https://doi.org/10.4236/ajac.2017.87034

Received: May 10, 2017

Accepted: July 3, 2017

Published: July 6, 2017

Copyright $\odot 2017$ by authors and Scientific Research Publishing Inc. This work is licensed under the Creative Commons Attribution International License (CC BY 4.0).

http://creativecommons.org/licenses/by/4.0/ (c) (i) Open Access

\begin{abstract}
Budesonide is a corticosteroid used for the treatment of asthma via various matrices and inhalation mechanisms. An unknown peak of Budesonide aqueous formulation has been investigated during stability study wherein the impurity level observed around $0.1 \%$ well below the threshold $0.5 \%$. The approach to identify anonymous species was adopted as first to generate the impurity in sample, isolate, enrich and was subjected to LC-MS/MS and NMR for spectral studies. Based on the spectral data the anonymous species were identified as a "Lumibudesonide" ((5aR,5bS,5cS,6S,7aS,7bS, 10aR,11aS, 11bS)6-hydroxy-7b-(2-hydroxyacetyl)-5b,7a-dimethyl-9-propyl 1,5a,5b,5c, 6,7,7a, 7b, 10a,11, 11a,11b dodecahydrocyclopenta[2",3"]cyclopropa [1",2":3', 4']benzo $\left[1^{\prime}, 2^{\prime}: 4,5\right]$ indeno $[1,2-\mathrm{d}][1,3]$ dioxol-5(2H)-one), which is observed in photolysis of Budesonide.
\end{abstract}

\section{Keywords}

Budesonide, Lumibudesonide, Photodegradation, LC-MS/MS, NMR, Degradation Study

\section{Introduction}

Impurity profiling of pharmaceutical active ingredients is an essential part of the research and developmental cycle. Regulatory agencies consider impurity profiling critical to ensure safety and efficacy of pharmaceutical dosage forms. Impurities observed in a drug substance or in a drug product need to be identified when their levels exceed certain regulatory thresholds with respect to their maxi- 
mum daily dose [1] [2].

Budesonide is a synthetic glucocorticoid which has been mainly used to treat asthma and as prophylactic therapy [3]. The impurities are originating from the drug substance most commonly originate within the synthetic process or degradation [4]. Further to identify the impurities, many difficulties are arising like, compound has poor to no UV absorbance whether due to the lack of chromophore or low level of impurity concentration exhibits poor UV spectral quality [5]. The utilization of UV or PDA data alone for impurity analysis is inadequate. The stereochemistry of the compounds adds a common challenge with impurity profiling; isolation of impurities at such minute amount can be extremely tedious, time consuming, and difficult. Hence mass spectrometry plays a central role in our approach rather than the use of only ultra-violet detection.

For identification of an unknown species, we have developed an approach that combines degradation studies, isolation and enriched the impurity and subjected to NMR, UV and mass spectroscopy for elucidating the unknown impurity structure. Based on the fragmentation pathways by LC-MS/MS, analysis designed the relevant degradation mechanism. After setting up the relevant degradation mechanism sample is analysed on HPLC with Photo-Diode-Array (PDA) detector to estimate the quantity and observe the PDA Scan.

The information derived from LC-MS/MS and UV spectra is used to establish the possible degradation mechanism by which the impurity would be formed. Typically, a stress study (or forced degradation) is carried out using acid, base, heat, oxidation, reduction and photo-irradiation, etc. Frequently, the very fact that a degradant can be generated from a stress study would verify the degradation mechanism, from which the structure of the unknown degradant may be inferred with high confidence level. In such cases the NMR spectroscopy is used to confirm the structure deduced from the outcome of the LC-MS/MS analysis and forced degradation study.

Moreover, the Morrison established through a series of elegant papers [6] [7] [8] [9] that intramolecular energy transfer (both singlet-singlet and triplet-triplet) occurred from the phenyl "antenna" to C17 keto group by the way of throughbond mechanism. This has led to a different photochemistry observed by the direct excitation of ketone chromophore. Albini et al. [10] [11] have demonstrated non-communicating reaction paths in pregna-1, 4-diene-3, 20-dione. Since many steroidal drugs are commonly used and several reports on their phototoxic effects have been reported [12] [13] [14] [15], it was expected that such photochemical mechanisms might have relevance for the mechanism of phototoxicity.

\section{Experimental}

\subsection{Materials}

The chemicals and reagents used for the analysis and purification purpose of Budesonide and degradation impurity:

Acetonitrile (HPLC grade), Supplier: Rankem, Avantor performance material Ltd, India; Methanol (HPLC grade), Supplier: Rankem, Avantor performance 
material Ltd, India; Acetonitrile (LCMS grade), Supplier: Biosolve Chimie SARL, France, Water: Highly pure Milli Q water was used with the help of Millipore Milli-Q plus purification system, Budesonide active pharmaceutical ingredient, Source: manufactured by Farmabios Italy, Budesonide Respules, Source: manufactured by Cipla Ltd, India.

\subsection{LC-PDA and LC-MS/MS Analysis}

The HPLC analysis was performed on Agilent 1200 series equipped with PDA detector. The LC-MS/MS analysis was performed on a waters Xevo QTof mass spectrometer interfaced to waters Acquity UPLC equipped with a UV detector. The sample were prepared in concentration $\sim 80 \mathrm{ppm}$ with diluent (ration of water: acetonitrile $(7: 3 \mathrm{v} / \mathrm{v}))$. The HPLC separation was carried out on a Hypersil BDS C18 $4.6 \mathrm{~mm} \times 100 \mathrm{~mm}, 3 \mu$ column at ambient temperature with $100 \mu \mathrm{l}$ injection volume, using a mobile phase system consisting of A, water and B, acetonitrile. The analyses were performed at ambient temperature with a flow rate of $1.0 \mathrm{~mL} / \mathrm{min}$ and a gradient program varied according to the following program: 0 min (22\% B), 6 min (22\% B), 15 min (30\% B), 40min (30\% B), 50 min $(40 \% \mathrm{~B}), 67 \mathrm{~min}(40 \% \mathrm{~B}), 68 \mathrm{~min}(22 \% \mathrm{~B})$ and $80.0 \mathrm{~min}(22 \% \mathrm{~B})$. The LC flow for the mass spectrometer was split at a $\sim 60: 40$ ratio after the UV detector; about $400 \mu \mathrm{L} / \mathrm{min}$ of the LC flow was directed into the MS detector. UV spectrum was collected at $254 \mathrm{~nm}$. The QTof mass spectrometer was operated at positive V electrospray mode with the following source parameters: cone gas $10 \mathrm{~L} / \mathrm{hr}$, desolvation gas $1000 \mathrm{~L} / \mathrm{hr}$, source temperature $120^{\circ} \mathrm{C}$, desolvation temperature $350^{\circ} \mathrm{C}$, capillary voltage $3 \mathrm{Kv}$, sampling cone $25^{\circ} \mathrm{C}$ and extraction cone 4.0. The time-of-flight (TOF) MS analyzer was operated with $\sim 4000$ full width half maximum resolution and was calibrated externally with a sodium iodide solution. spectra were acquired at $1 \mathrm{scan} / \mathrm{s}$ scan rate and $0.1 \mathrm{~s}$ inter-scan time.

\subsection{Photodegradation Study and Isolation of Impurity}

An unknown species was generated by preparing a solution at higher concentration as $0.1 \mathrm{gm}$ Budesonide active in a mixture of $2 \mathrm{~mL}$ Acetonitrile. The solution was irradiated under a UV lamp at $254 \mathrm{~nm}$ for $8 \mathrm{~h}$. The UV degradation product was isolated using a Dionex UltiMate 3000 Titanium Bio-LC equipped with PDA detector, autofraction collector and $250 \mu$ loop LC system. The isolation was carried out by using same chromatographic method outlined in Section 2.2. only injection volume used as $150 \mu \mathrm{l}$ instead of $100 \mu$ l. Fractions were collected in the window of 48 - 49 minutes by giving program to autofraction collector and dried the collected fraction on a RotaVap to remove the organic solvent followed by complete evaporation of the remaining aqueous solvent in a freeze dryer (Virtis).

\subsection{Unknown Impurity Characterization by NMR}

The NMR experiments were performed on Varian Spectrometer operating at $500 \mathrm{MHz}$ at $25^{\circ} \mathrm{C}$ using deuterated solvent $\mathrm{CDCl} 3$ with Tetra methyl silane as an internal standard. The $\mathrm{H}^{1}$ chemical shift values were reported on the $\delta$ scale in 
$\mathrm{ppm}$, relative to Tetramethylsilane $(\delta=0.0 \mathrm{ppm})$. The sample was prepared in $\mathrm{CDCl}_{3}$ in concentration of $\sim 2 \mathrm{mg} / \mathrm{ml}$.

\subsection{Toxicological Evaluation by DEREK Nexus Software}

No direct toxicological data is available on public domain for the identified impurity.

Based on Derek Nexus: 4.1.0, Nexus: 2.0.0, an expert knowledge based SAR program which contains expert rules (derived from public and proprietary data) in toxicology and applies the rules to make predictions about the toxicity of chemicals, which is widely-respected and accepted for the assessment of mutagenicity has yield following outputs for Budesonide and impurity:

- Chromosome damage in vitro in bacterium is impossible;

- Chromosome damage in vitro in mammal is plausible;

- Mutagenicity in vitro in bacterium is plausible;

- Mutagenicity in vitro in mammal is plausible;

- Non-specific genotoxicity in vitro in mammal is plausible;

- Skin sensitization in mammal is plausible.

\section{Results and Discussion}

\subsection{Impurity Identification by LC-MS/MS and HPLC-PDA}

The anonymous species at retention time $\sim 48.3$ (RRT 1.9) (Figure 1(a)) was observed in Budesonide drug product $\sim 0.1 \%$ well below the threshold of $0.5 \%$. The impurity was observed $\sim 4 \%$ after photo-irradiation in presence of organic solvent such as Acetonitrile/Methanol when analysed by a compendial method. It was clear from the LC-MS/MS spectral observation the RRT about 1.9 peak is an rearranged isomer of Budesonide (since both have the same molecular ions at $\mathrm{m} / \mathrm{z}$ 431). The UV spectrum of Budesonide showed a maximum absorbance band at $244 \mathrm{~nm}$ (Figure 1(b)), due to the dienone (conjugated double bonds with carbonyl group) in the A-ring of Budesonide. While the impurity peak showed a markedly different UV spectrum, the two new absorbance bands appears at $\sim 278 \mathrm{~nm}$ and $\sim 334 \mathrm{~nm}$ respectively and $244 \mathrm{~nm}$ bands shifts to $238 \mathrm{~nm}$ (Figure 1(c)). In the MS spectrum of Budesonide (Figure 1(d)) showed, protonated (m/z 431), sodiated (m/z 453) and potassiated (m/z 469) molecular ions. Further it is fragmented in positive volt for structure elucidation, were several fragments ions produced of the protonated molecular ion (Figure 1(f)), including $\mathrm{m} / \mathrm{z} 413$ (loss of $\mathrm{H}_{2} \mathrm{O}$ ), $\mathrm{m} / \mathrm{z} 377$ (loss of $\mathrm{CH}_{3} \mathrm{CH}_{2} \mathrm{CH}_{2} \mathrm{CH}$ ), m/z 395 (loss of $\mathrm{CH}_{3} \mathrm{CH}_{2} \mathrm{CO}_{2} \mathrm{H}$ and $\mathrm{H}_{2} \mathrm{O}$ ), $\mathrm{m} / \mathrm{z} 341$ (loss of $\mathrm{H}_{2} \mathrm{O}, \mathrm{CH}_{3} \mathrm{CH}_{2} \mathrm{CO}_{2} \mathrm{H}$ and $\mathrm{H}_{2} \mathrm{O}$ ), $\mathrm{m} / \mathrm{z}$ 323 (loss of $\mathrm{H}_{2} \mathrm{O}, \mathrm{CH}_{3} \mathrm{CH}_{2} \mathrm{CO}_{2} \mathrm{H}$ and $2 \mathrm{H}_{2} \mathrm{O}$ ) and another daughter ions $\mathrm{m} / \mathrm{z} 305$, $\mathrm{m} / \mathrm{z} 295, \mathrm{~m} / \mathrm{z} 277, \mathrm{~m} / \mathrm{z} 263, \mathrm{~m} / \mathrm{z} 225, \mathrm{~m} / \mathrm{z}$ 173, m/z 147, m/z 121 (Scheme 1). Same fragmentation pattern were observed in the MS/MS spectrum of unknown species (Figure $1(\mathrm{~g})$ ). The above mass spectroscopic study reveals that the unknown species has a chemical formula of $\mathrm{C}_{25} \mathrm{H}_{34} \mathrm{O}_{6}$, which is the same as that of Budesonide. Its protonated, ammoniated, sodiated and potassiated molecular 


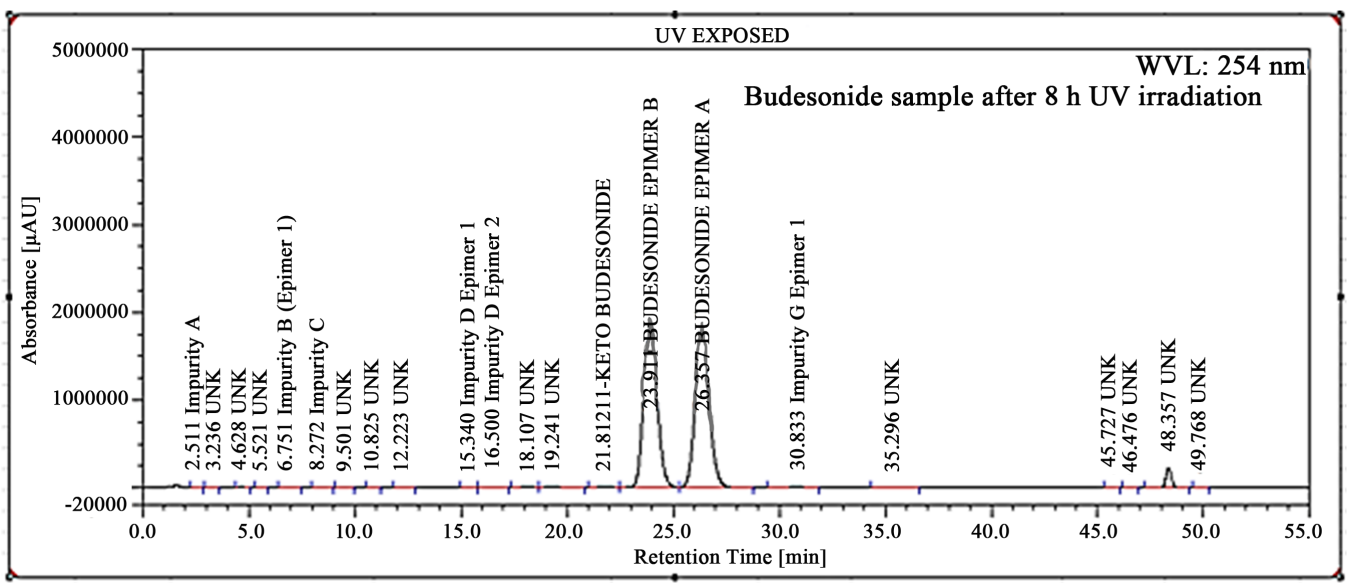

(a)

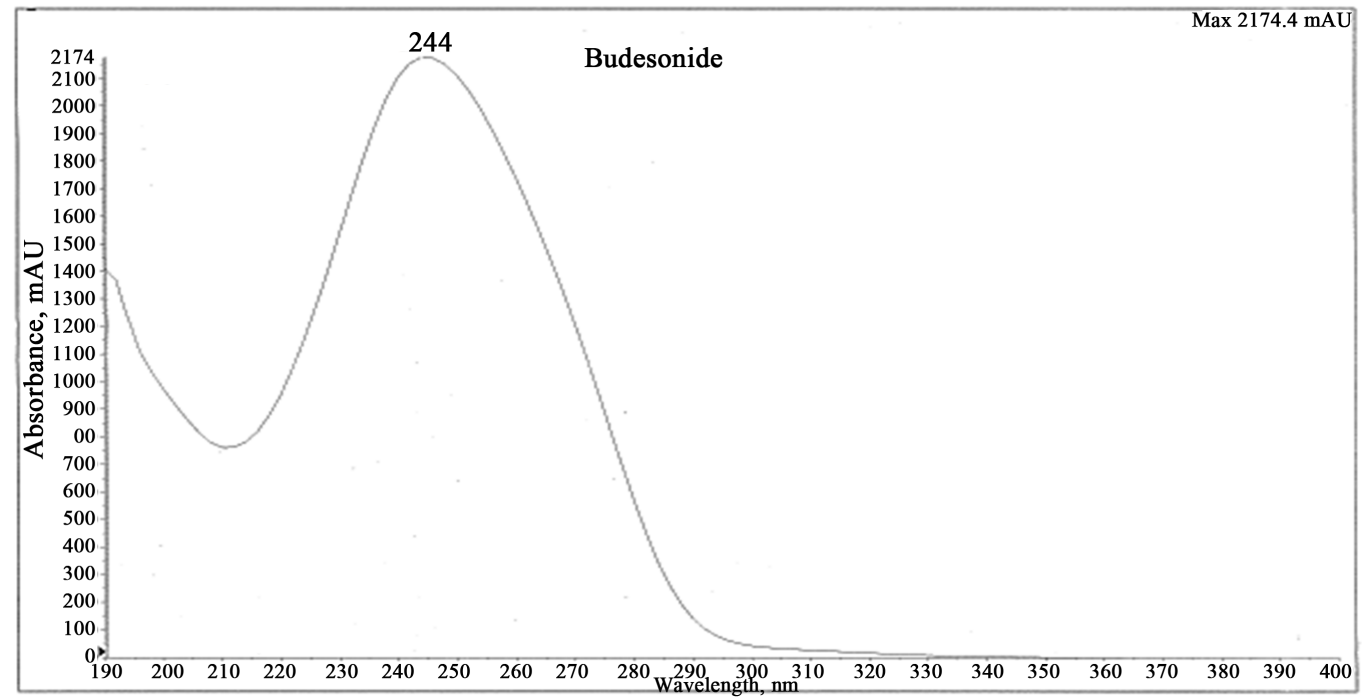

(b)

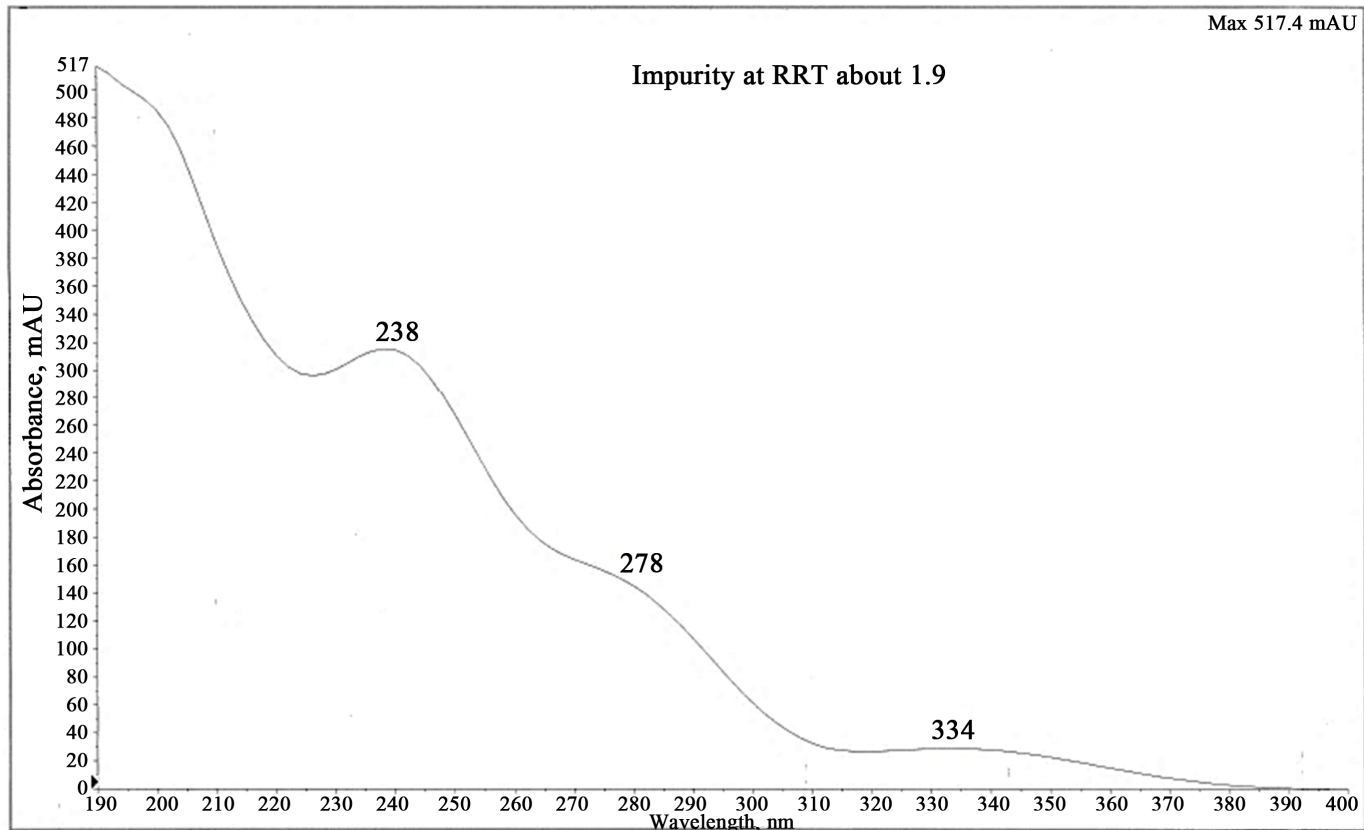

(c) 


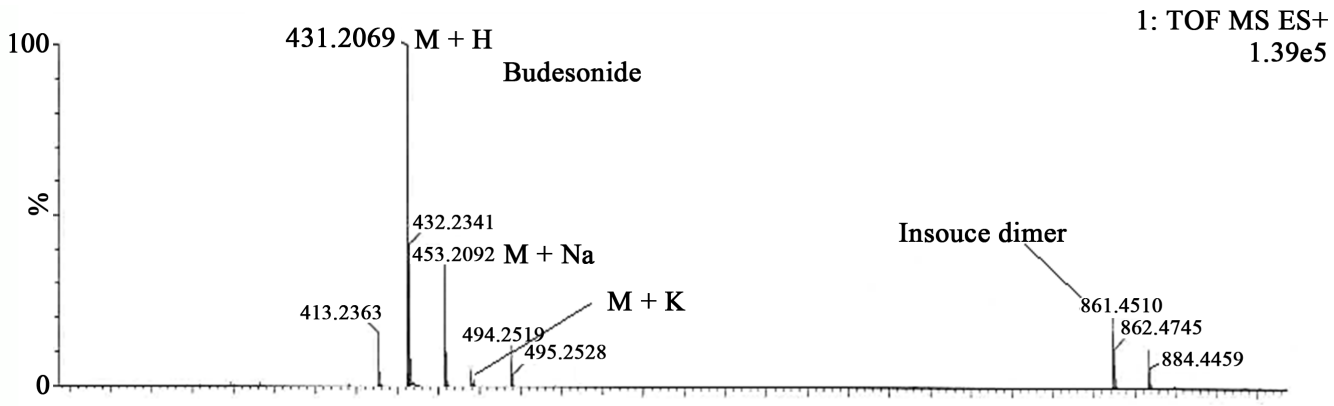

(d)

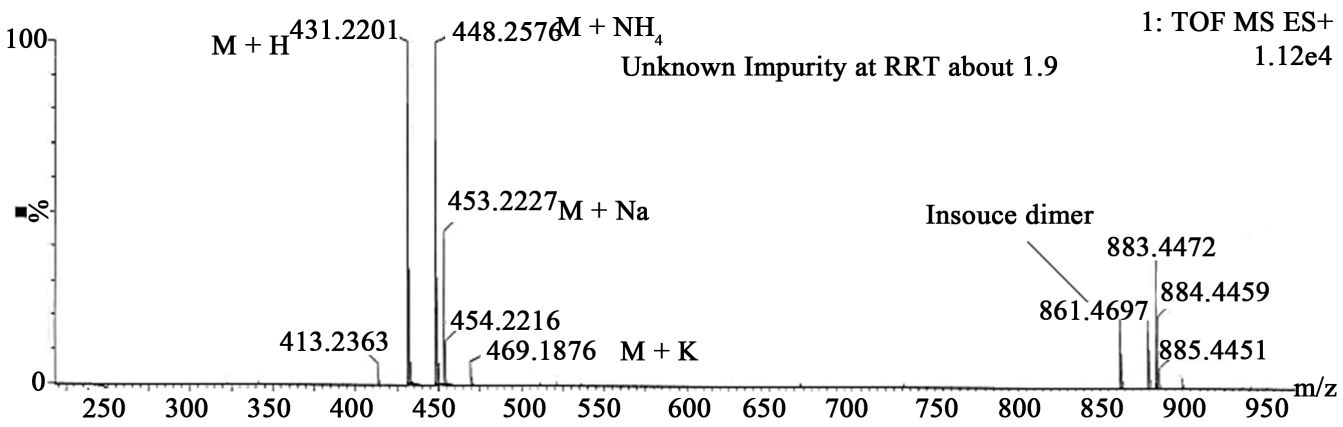

(e)

Fragmentation pattern of Budesonide

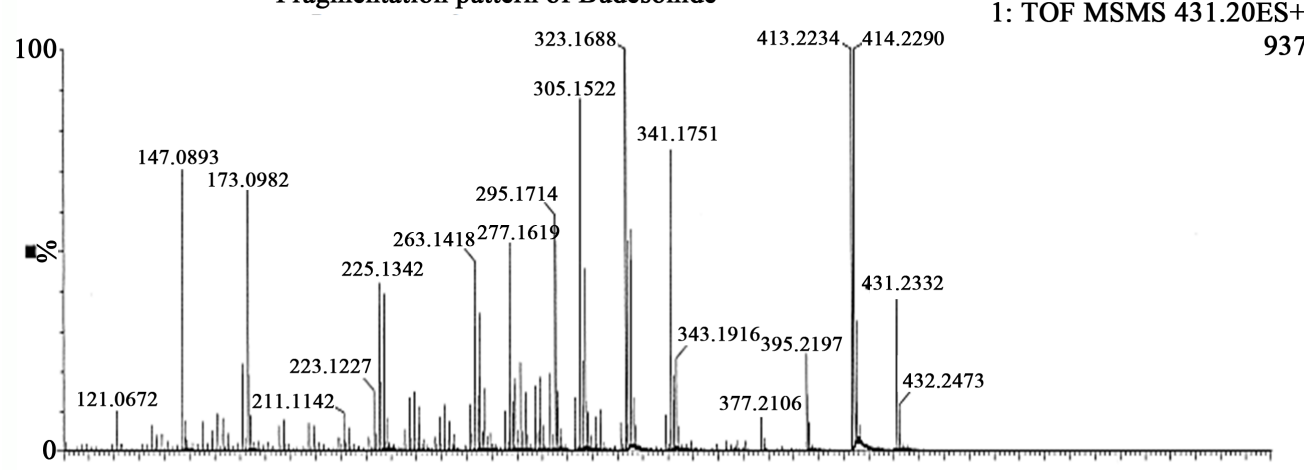

(f)

Fragmentation pattern of impurity at RRT about 1.9

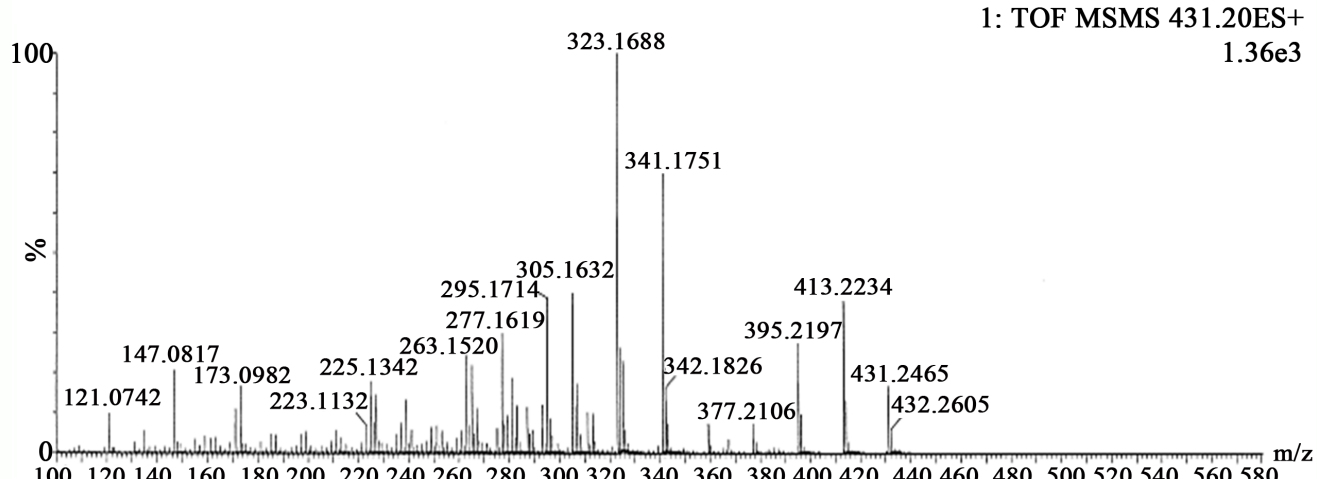

1: TOF MSMS 431.20ES+

$100120140 \quad 160180200220240260280300320340360380400420 \quad 440460480500520540560580$

(g)

Figure 1. (a) UV $254 \mathrm{~nm}$ chromatogram of the Budesonide sample exposed to UV-irradiation. The RRT about 1.9 unknown peak was observed at retention time $\sim 48.3$ minutes. UV absorbance spectra of budesonide and unknown species are shown in (b) and (c) respectively; MS spectra of budesonide and unknown species are shown in (d) and (e), respectively; fragmentation pattern of Budesonide and unknown species shown in (f) and (g) respectively. 

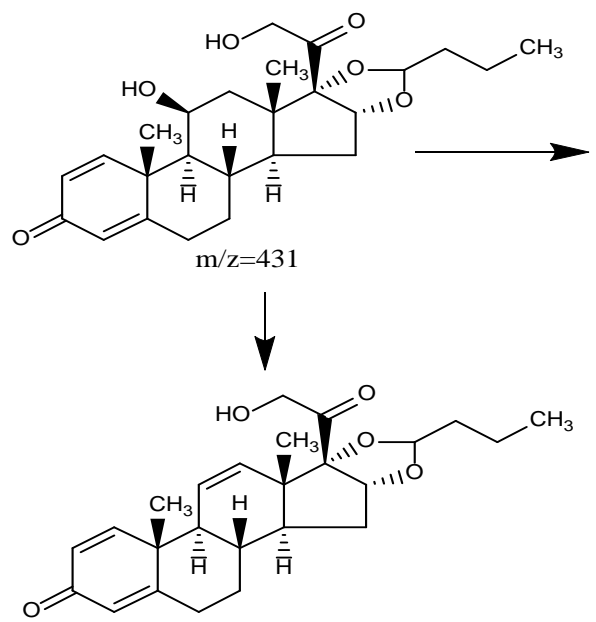

$\mathrm{m} / \mathrm{z}=413$

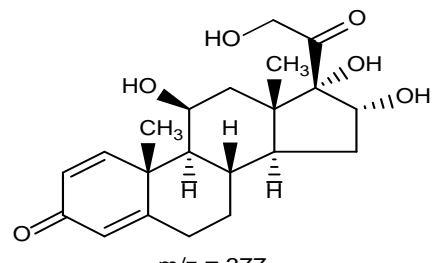

$\mathrm{m} / \mathrm{z}=377$

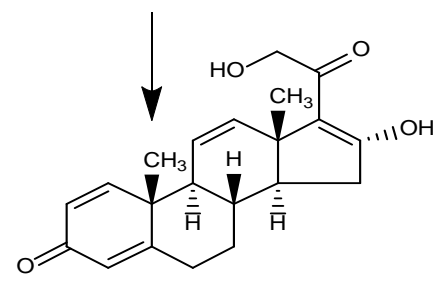

$\mathrm{m} / \mathrm{z}=341$

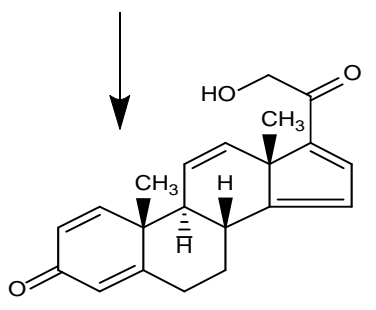

$\mathrm{m} / \mathrm{z}=323$

Scheme 1. Fragmentation pathways of Budesonide.

ions $\mathrm{m} / \mathrm{z} 431, \mathrm{~m} / \mathrm{z} 448, \mathrm{~m} / \mathrm{z} 453$ and $\mathrm{m} / \mathrm{z} 469$, respectively as summarized in Table 1 . The $\mathrm{m} / \mathrm{z} 861$ ion observed in both Budesonide as well as in unknown impurity mass spectrum (Figure 1(d) and Figure 1(e)) was assigned as a dimer which is formed due to the in-source dimerization in positive volt with ESI mode. The MS/MS fragmentation of the $\mathrm{m} / \mathrm{z} 861$ ions produced only a $\mathrm{m} / \mathrm{z} 431$ as the product ion (data not shown) suggesting that it was indeed a weakly bound gas phase adduct between two molecular ions same were observed in unknown impurity with sodiated molecular ion $\mathrm{m} / \mathrm{z} 883$. These mass spectroscopic data clearly suggested that an unknown impurity at RRT about 1.9 is a rearranged product of Budesonide. Since Budesonide shows the maximum absorbance at $\sim 244 \mathrm{~nm}$ is due to the characteristic conjugated double bonds in the A-ring, the impurity at RRT about 1.9 is formed due to the rearrangement of the dienone ring which clearly indicated in UV spectra (Figure $1(c)$ ).

\subsection{Degradation Study Based on LC-MS/MS Results}

To test the above proposition the impurity at RRT about 1.9 was isolated by HPLC discussion outlined in Section 2.3. The possible formation mechanism of the unknown species, was found that the unknown peak was observed only when the sample solution was exposed to UV light in presence of organic solvents like acetonitrile/methanol. Since the unknown species has the same molecular formula as the drug substance Budesonide, but with a completely different UV absorbance spectrum. It is likely that the unknown species is a degradant of Budesonide through photo-isomerization. Hidaka et al. [16] reported a photo- 
Table 1. Accurate mass measurement results of unknown species.

\begin{tabular}{cccc}
\hline $\begin{array}{c}\text { Observed molecular } \\
\text { weight }(\mathrm{m} / \mathrm{z})\end{array}$ & $\begin{array}{c}\text { Theoretical } \\
\text { mass }\end{array}$ & $\begin{array}{c}\text { Chemical } \\
\text { formula }\end{array}$ & $\begin{array}{c}\text { Molecular } \\
\text { ion with adduct }\end{array}$ \\
\hline 431.2201 & 431.2428 & $\mathrm{C}_{25} \mathrm{H}_{35} \mathrm{O}_{6}$ & $(\mathrm{M}+\mathrm{H})^{+}$ \\
448.2576 & 448.2682 & $\mathrm{C}_{25} \mathrm{H}_{38} \mathrm{O}_{6} \mathrm{~N}$ & $\left(\mathrm{M}+\mathrm{NH}_{4}\right)^{+}$ \\
453.2227 & 453.2247 & $\mathrm{C}_{25} \mathrm{H}_{34} \mathrm{O}_{6} \mathrm{Na}$ & $(\mathrm{M}+\mathrm{Na})^{+}$ \\
469.1876 & 469.1987 & $\mathrm{C}_{25} \mathrm{H}_{34} \mathrm{O}_{6} \mathrm{~K}$ & $(\mathrm{M}+\mathrm{K})^{+}$ \\
\hline
\end{tabular}

induced, isomeric degradant of Betamethasone with an altered A-ring structure, which had a maximum UV absorbance band at $\sim 270 \mathrm{~nm}$. Considering the facts that there is no alteration of functional group which is already confirmed by mass spectroscopy as well as Budesonide do not contribute significantly to its UV absorbance and that the RRT about 1.9 unknown species has a maximum UV absorbance bands at $\sim 238 \mathrm{~nm}, \sim 278 \mathrm{~nm}$ and $\sim 334 \mathrm{~nm}$, respectively (Figure $1(\mathrm{c})$ ), it was suspected that the unknown species might be the derivative of the photo-degradant of budesonide.

\subsection{Photodegradation Study}

The UV irradiation discussion outlined in Section 2.3 was performed, this strategy is planned for generation of an unknown impurity at RRT about 1.9 under UV irradiation condition. The chromatograms obtained from HPLC and LC-MS/MS analysis of sample before and after the UV irradiation are shown in (Figure 2(a) and Figure 2(b)). An unknown species clearly appeared $\sim 4 \%$ yield after the $8 \mathrm{~h} \mathrm{UV}$ irradiation at $254 \mathrm{~nm}$ in presence of Acetonitrile. The mass and UV spectrum of species generated in photo-irradiation shows same molecular weight, fragments and UV spectrum with that of Budesonide observed in sample solution (data not shown). The unknown impurity isolated and spiked with the sample which was exactly co-eluted with the retention time of unknown impurity, which shows same mass and UV spectrum (data not shown).

Moreover, as such formulation suspension also subjected to photostability (as per ICH guideline i.e. 1.2 million lux and $200 \mathrm{watt} / \mathrm{m}^{2}$ ) wherein the impurity observed below the threshold of $0.5 \%$. The photodegradant of Budesonide generated from the photo stress study was purified and then characterized by UV spectra, NMR and mass spectroscopy.

\subsection{Characterization of Unknown Impurity by NMR}

An unknown impurity formed by UV irradiation of Budesonide isolated and purified discussion outlined in Section 2.3. The NMR spectra of the isolated species was confirmed that it is indeed Photoproduct (Scheme 2). Which is a photo-induced isomeric degradant of Budesonide (Scheme 2).

In a separate study, Fahmy [17] reported Dexamethsone, alpha-oriented C16 methyl group as opposed to the beta-oriented for betamethasone can undergo a similar UV photo-induced isomerization producing lumidexamethsone. A plau- 
A. Bhutnar et al.

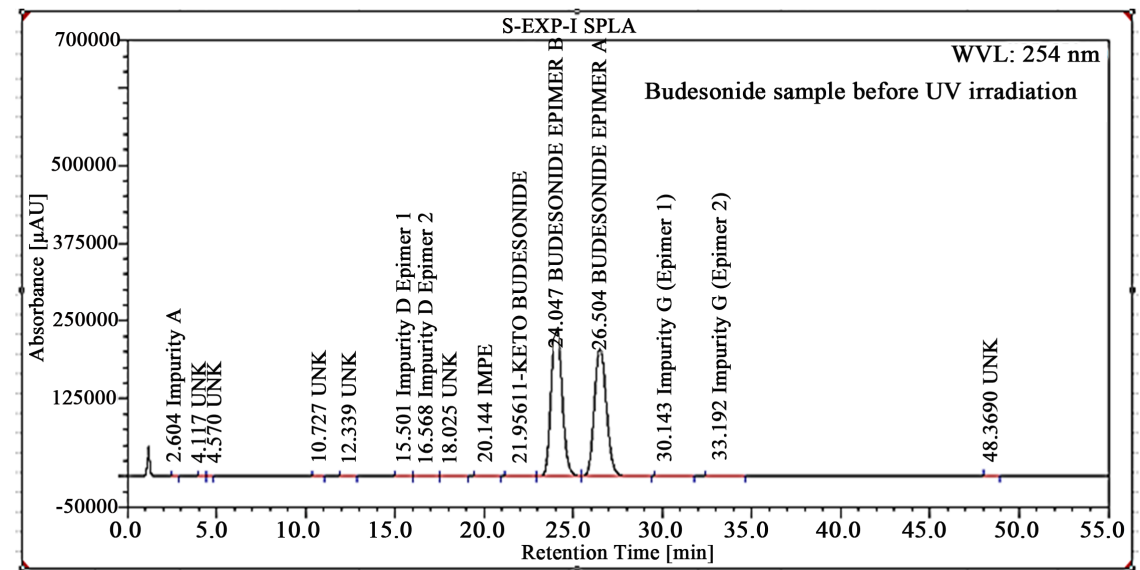

(a)

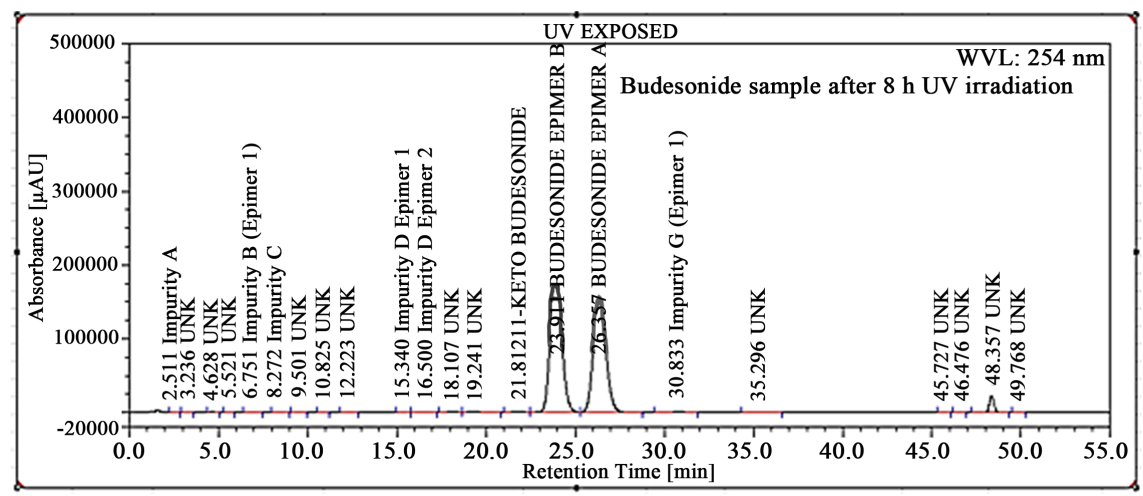

(b)

Figure 2. UV $254 \mathrm{~nm}$ chromatograms of Budesonide (a) before UV irradiation and (b). Unknown impurity at RRT about 1.9 was observed at retention about 48.3 minutes (RRT 1.9) after $8 \mathrm{~h} \mathrm{UV}$ irradiation at $254 \mathrm{~nm}$ with Acetonitrile.

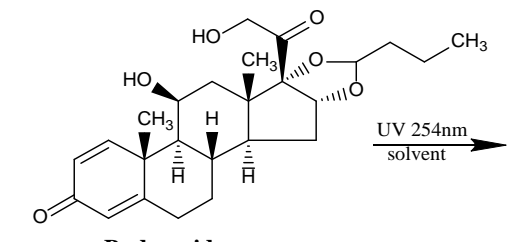

Budesonide

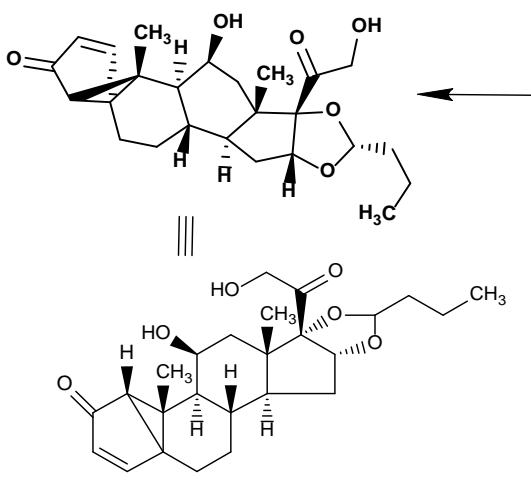

Lumibudesonide

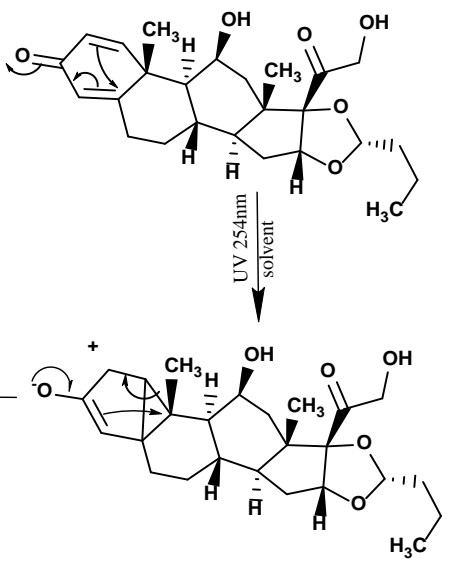

$\mathrm{H}_{3} \mathrm{C}^{\prime}$

Scheme 2. Lumibudesonide. 
sible mechanism for the formation of lumibudesonide is thus proposed in Scheme 2, based on the photoisomerization mechanism of dexamethasone [17] and prednisone [18]. During this photo-isomerization process, a new bond is formed between $\mathrm{C} 15$ and $\mathrm{C} 17$ (Scheme 3) under UV irradiation, leading to the formation of lumibudesonide (Scheme 3).

${ }^{1} \mathrm{H}$ NMR spectrum of Impurity at RRT about 1.9 (Figure 3(a)) and ${ }^{1} \mathrm{H}$ NMR spectrum Budesonide (Figure 3(b)). The spectrum was obtained on the $\mathrm{CDCl}_{3}$ solution of the isolated impurity on a Varian 500 spectrometer operating at a proton frequency of $500 \mathrm{MHz}$. It was found that Budesonide into Lumibudesonide (Figure 3(a)).

For comparison, the NMR data (Figure 3(a) and Figure 3(b)) for Budesonide relevant for assignment of the structure of photoproducts are reported here.

Budesonide Epimer A and B: HPLC: RT Epimer B 23.9 min and for Epimer A $26.3 \mathrm{~min} ;{ }^{1} \mathrm{H}$ NMR $\left(500 \mathrm{MHz}, \mathrm{CDCl}_{3}\right), \delta 7.25(\mathrm{~d}, 1 \mathrm{H}, \mathrm{H}-1, \mathrm{~J}=10.1 \mathrm{~Hz}) ; 6.28$

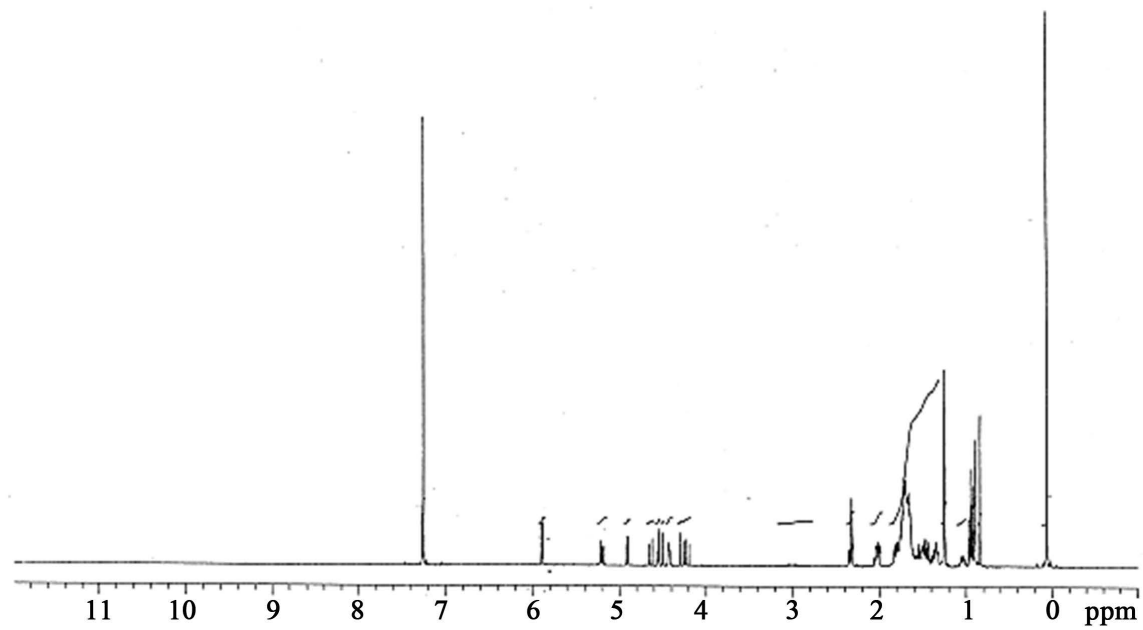

(a)

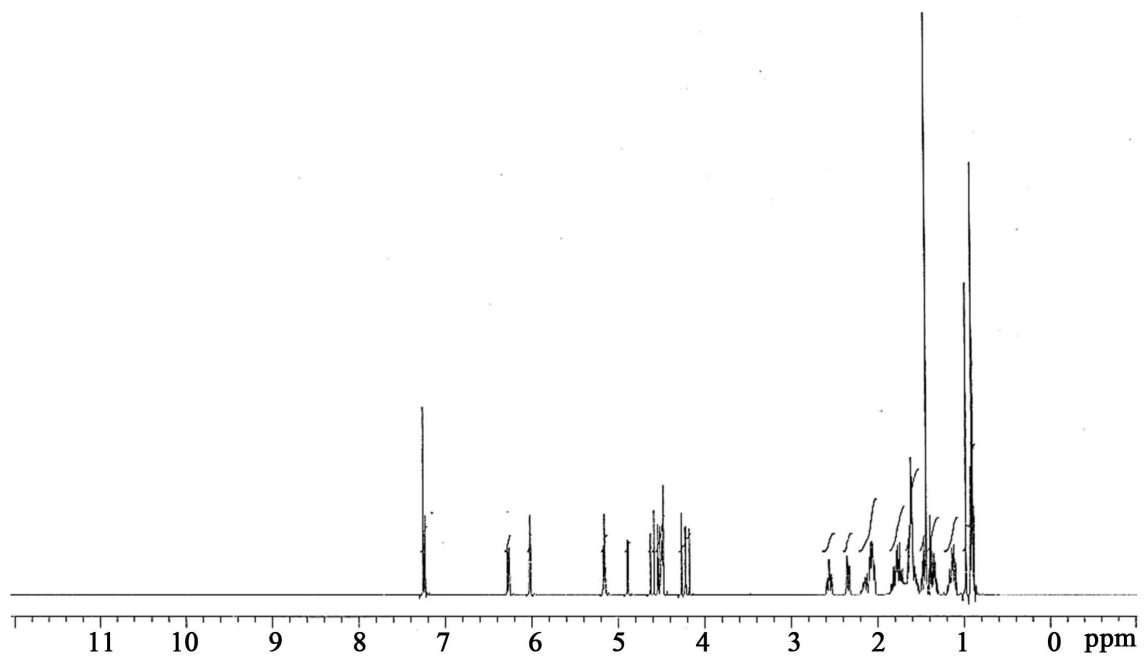

(b)

Figure 3. NMR spectrum: A plot of chemical shift in ppm (x-axis) versus signal intensity (y-axis). (a) Budesonide impurity at RRT about 1.9; (b) Budesonide drug substance. 
(d, 1H, H-2, J = $10.1 \mathrm{~Hz}) ; 6.01(\mathrm{~s}, 1 \mathrm{H}, \mathrm{H}-4) ; 4.6(\mathrm{~d}, 1 \mathrm{H}, \mathrm{H}-30, \mathrm{~J}=21.2 \mathrm{~Hz}) ; 4,29$ (br s, $1 \mathrm{H}, \mathrm{H}-10) ; 4.55(\mathrm{t}, 1 \mathrm{H}, \mathrm{H}-21, \mathrm{~J}=10.1 \mathrm{~Hz}$ ). The zone between $\delta 2.6$ and $\delta$ $0.8 \mathrm{ppm}$ contains almost all protons of rings $\mathrm{B}, \mathrm{C}$, and $\mathrm{D}$ and the methyl groups, which are not involved in the photomodification. MS: $431[\mathrm{M}+\mathrm{H}]+$.

Photoproduct: HPLC: RT $49.26 \mathrm{~min} ;{ }^{1} \mathrm{H}$ NMR $\left(500 \mathrm{MHz}, \mathrm{CDCl}_{3}\right), \delta 7.31$ (d, $1 \mathrm{H}, \mathrm{H}-4, \mathrm{~J}=5.5 \mathrm{~Hz}) ; 5.92(\mathrm{~d}, 1 \mathrm{H}, \mathrm{H}-3, \mathrm{~J}=5.0 \mathrm{~Hz}) ; 4.62(\mathrm{~d}, 1 \mathrm{H}, \mathrm{H}-30, \mathrm{~J}=21.2$ $\mathrm{Hz}$ ); 4.30, (br s, 1H, H-10); 4.57 (t, 1H, H-21, J = 10.1 Hz). MS: $431[\mathrm{M}+\mathrm{H}]+$.

The ${ }^{1} \mathrm{H}$ NMR spectrum lacks the signals at 7.25, 6.28, and 6.01 (protons of carbon no. 17, 18, and 20, of the parent drug, respectively) (Scheme 3) and shows two new doublets, coupled with each other with a constant of J value 5.5 $\mathrm{Hz}$ (Figure 3(a) and Figure 3(b)). Therefore, ring A only has two vinyl protons, the third proton being now aliphatic. No changes occurred at the level of protons of carbon no 10 and 30. The molecular weight does not change with respect to the parent drug. These data suggest a rearrangement of ring A of Budesonide to give the "Photo rearranged product"

On the basis of the spectral data, photoproduct derived from a well-known two-step intramolecular rearrangement of ring A typical of the cyclodienones (Scheme 4) to give the so called photolumi product [19].

\subsection{Toxicological Interpretation of the Impurity}

The toxicological assessment on Derek Nexus: 4.1.0, Nexus: 2.0.0, an expert

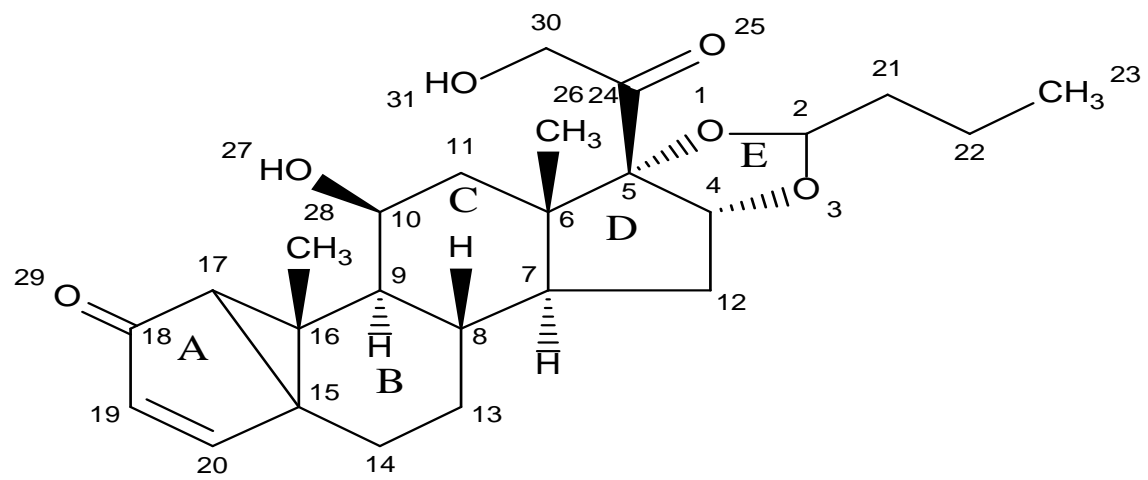

Scheme 3. Lumibudesonide.

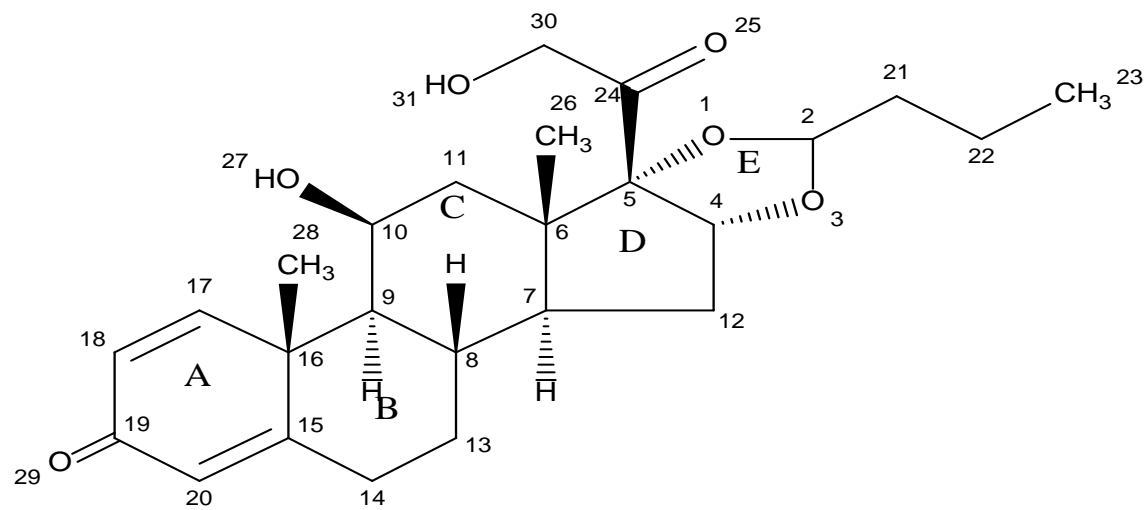

Scheme 4. Budesonide. 
knowledge based SAR program discussion outlined in Section 2.5 was performed. The outputs observed for Lumibudesonide are concordant with those observed for Budesonide and is controlled by taking adequate measures.

\section{Conclusion}

The impurity peak observed at RRT about 1.9 is generated in the photodegradation and it is an isomeric impurity formed due to rearrangement induced by UV-irradiation. It is characterised by using cutting edge technology like LCMS/MS and NMR and it was identified as Lumibudesonide ((5aR,5bS,5cS, $6 \mathrm{~S}$, 7aS,7bS,10aR,11aS,11bS)-6-hydroxy-7b-(2-hydroxyacetyl)-5b,7a-dimethyl-9-propyl-1,5a,5b,5c,6,7,7a,7b,10a,11,11a,11b dodecahydrocyclopenta [2",3"]cyclopropa[1",2":3',4']benzo [1',2':4,5]indeno [1,2-d][1,3] dioxol-5(2H)-one).

\section{References}

[1] ICH Harmonised Tripartitie Guideline, Impurities in New Drug Substances, Step4 Version, Dated 25 October 2006.

[2] ICH Harmonised Tripartitie Guideline, Impurities in New Drug Products, Step 4Version, Dated 2 June 2006.

[3] Avery, M., Detre, G., Yasuda, D., Chao, W.R., Tanabe, M., Crowe, D., Peter, R. and Chong, W. (1990) Synthesis and Antiinflammatory Activity of Novel 12.beta.-Substituted Analogs of Betamethasone. Journal of Medicinal Chemistry, 22, 1852-1858. https://doi.org/10.1021/jm00169a004

[4] Davies, A., Jones, M.D., Marsden-Edward, E., Castro-Parez, J., Plumb, R.S. and Shockcoor, J. An Automated Approach for Pharmaceutical Impurity Profiling Waters Corporation, Manchester UK. Waters Corporation, Milford.

[5] Potts III, W. and Jones, M. Robert Plumb Waters Corporation, Milford.

[6] Wu, Z.Z., Nash, J. and Morrison, H. (1992) Organic Photochemistry. 97. AntennaInitiated Photochemistry in Polyfunctional Steroids. Photoepimerization of 3.alpha.(Dimethylphenylsiloxy)-5.alpha.-Androstane-6,17-Dione and Its 3.beta. Isomer by Through-Bond Exchange Energy Transfer. Journal of the American Chemical Society, 114, 6640-6648. https://doi.org/10.1021/ja00043a005

[7] Wu, Z.Z. and Morrison, H. (1992) Organic Photochemistry. 95. Antenna-Initiated Photochemistry of Distal Groups in Polyfunctional Steroids. Intramolecular Singlet and Triplet Energy Transfer in 3.alpha.-(Dimethylphenylsiloxy)-5.alpha.-Androstan-17-One and 3.alpha.-(Dimethylphenylsiloxy)-5.alpha.-Androstane-11,17-Dione. Journal of the American Chemical Society, 114, 4119-4128. https://doi.org/10.1021/ja00037a013

[8] Morrison, H., Pallmer, M., Loeschen, R., Pandey, R., Muthuramu, K. and Maxwell, B. (1986) Organic Photochemistry. 68. Photochemistry of Polyfunctional Molecules. Intramolecular Aryl to Ketone Singlet Energy Transfer in the Trans- and Cis-Decalins, 7-keto-13.beta.-methyl-5,6,7,8,9,10,13.beta.,14.alpha.-Octahydrophenanthrene, and Its 14.beta. Isomer. Journal of Organic Chemistry, 51, 4676-4681. https://doi.org/10.1021/jo00374a032

[9] Wu, Z.Z. and Morrison, H. (1989) Photochemistry of Polyfunctional Molecules. Development of Antenna Chromophores for Self-Sensitized Photoreduction of Ketones. Photochemistry and Photobiology, 50, 525. https://doi.org/10.1111/j.1751-1097.1989.tb05558.x

[10] Ricci, A., Fasani, E., Mella, M. and Albini, A. (2001) Noncommunicating Photo- 
reaction Paths in Some Pregna-1,4-diene-3,20-diones. Journal of Organic Chemistry, 66, 8086-8093. https://doi.org/10.1021/jo015884z

[11] Ricci, A., Fasani, E., Mella, M. and Albini, A. (2003) General Patterns in the Photochemistry of Pregna-1,4-dien-3,20-diones. The Journal of Organic Chemistry, 68, 4361-4366. https://doi.org/10.1021/jo034070a

[12] Suzuki, T., Kato, T., Kitagaki, T., Ono, M., Shirakawa, K., Nagata, M. and Konishi, R. (1996) Dermatotoxicity Studies of Calcipotriol (MC903) Ointment: Primary Skin Irritation, Skin Sensitization, Phototoxicity and Skin Photosensitization. The Journal of Toxicological Sciences, 21, 475-484. https://doi.org/10.2131/jts.21.SupplementII_475

[13] Keknes, A., Jahn, P. and Lange, L. (1993) Local Tolerability of Topically Applied Methylprednisolone Aceponate. Journal of the American Academy of Dermatology, 28, 786-788. https://doi.org/10.1016/S0190-9622(09)80275-2

[14] Uchiyama, H., Tanaka, T., Uehara, N., Nakamura, M., Tsuji, M., Shinomiya, M. and Tanaka, H. (1992) Effects of Prednisolone Farnesylate (PNF) Gel on Skin and Ocular Mucosa. The Journal of Toxicological Sciences, 17, 283-312. https://doi.org/10.2131/jts.17.SupplementIII_283

[15] Albini, A. and Fasani, E. (1998) Drugs: Photochemistry and Photostability. Royal Society of Chemistry, Cambridge. https://doi.org/10.1039/9781847550712

[16] Hidaka, T., Huruumi, S., Tamaki, S., Shiraishi, M. and Minato, H. (1980) Studies on Betamethasone: Behavior of Betamethasone in Acid or Alkaline Medium, Photolysis, and Oxidation. Yakugaku Zasshi, 100, 72-80. https://doi.org/10.1248/yakushi1947.100.1_72

[17] Fahmy, O.T.Y. (1997) Generation, Isolation, Characterization and Analysis of Some Photolytic Products of Budesonide and Related Steroids. Doctoral Thesis, University of Mississippi, Oxford, MS.

[18] Williams, J.R., Moore, R.H., Li, R. and Blount, J.F. (1979) Structure and Photochemistry of Lumiprednisone and Lumiprednisone Acetate. Journal of the American Chemical Society, 101, 5019-5025. https://doi.org/10.1021/ja00511a036

[19] Williams, J.R., Moore, R.H., Li, R. and Weeks, C.M. (1980) Photochemistry of 11.alpha.- and 11.beta.-hydroxy Steroidal 1,4-dien-3-ones and 11.alpha.- and 11.beta.hydroxy Steroidal Bicyclo[3.1.0]hex-3-en-2-ones in Neutral and Acidic Media. The Journal of Organic Chemistry, 45, 2324-2331. https://doi.org/10.1021/jo01300a012

\section{Submit or recommend next manuscript to SCIRP and we will provide best service for you:}

Accepting pre-submission inquiries through Email, Facebook, LinkedIn, Twitter, etc. A wide selection of journals (inclusive of 9 subjects, more than 200 journals) Providing 24-hour high-quality service User-friendly online submission system Fair and swift peer-review system Efficient typesetting and proofreading procedure Display of the result of downloads and visits, as well as the number of cited articles Maximum dissemination of your research work

Submit your manuscript at: http://papersubmission.scirp.org/

Or contact ajac@scirp.org 